\title{
The British Society for Oral \& Maxillofacial Pathology conference 2019
}

The 2019 conference of the British Society for Oral \& Maxillofacial Pathology (BSOMP) was held in Dublin on 25 and 26 April.

The programme local organisers Esther O'Regan, Mary Toner and their team - to whom the Society is indebted - had arranged was an eclectic mix of clinicopathological research and audit with an original philosophical angle. The oral presentations covered topics ranging from the metabolic effects of $P$. gingivalis on keratinocytes in vitro to the assessment of diagnostic competence in histopathology.

The coffee and lunch breaks provided an opportunity to view the record number of 37 posters on display, for which several prizes were up for grabs. The symposium, 'Bone and Joints: Advances in Diagnostics \& Tissue Regeneration', was graced by two outstanding keynote speakers. First Professor Daniel Kelly of Trinity College Dublin spoke on biomaterials and 3D bioprinting for bone and joint regeneration. He was followed by Professor Adrienne Flanagan (University College

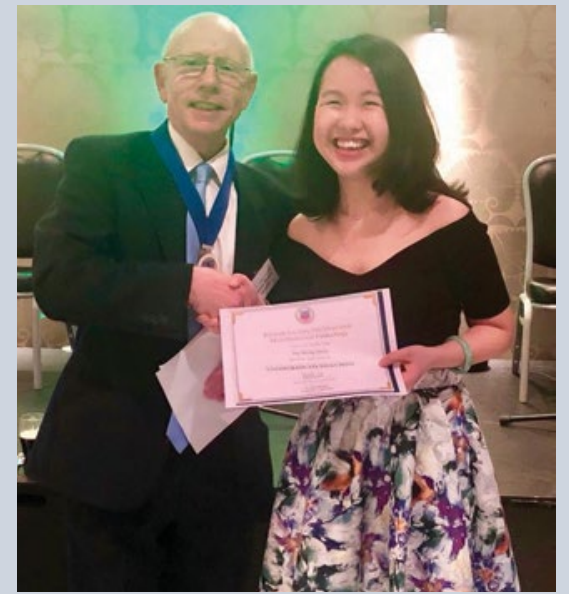

BSOMP President Bill Barrett presents Pei Rong Chua of Glasgow University with the Undergraduate Essay Prize for her entry on the subject of 'The role of the pathologist in the management of oral cancer'

London and the Royal National Orthopaedic Hospital, Stanmore), who gave two lectures on how genetic alterations in maxillofacial bone tumours facilitate histopathological diagnosis. Michael Comyn, broadcaster and founder of The Fearless Organisation, then ended the first day with a remarkable presentation on the psychology of leadership and resilience.

At the conference dinner the prizes were awarded to Pei Rong Chua (Glasgow, Undergraduate Essay Prize), Vivian Petersen Wagner (Sheffield, Research Prize), Paris Tamiolakis (Dublin, Clinical Prize) and Paul Hankinson (Sheffield, Dental Core Trainee Prize).

On Friday morning local consultant histopathologist Dr Niall Swan described his eye-opening experiences as founding member and erstwhile chairperson of the National Quality Improvement Programme in Histopathology in Ireland. The conference was completed with a slide seminar of challenging diagnostic cases, followed by the review session of the National Head and Neck Pathology External Quality Assurance Scheme, bravely chaired for the first time by Miranda Pring and Tim Bates. To get a trainee's perspective of the conference, read Yori Adegun's blog on the BSOMP website (www.bsomp.org.uk), where there is an abundance of information on oral and maxillofacial pathology.

\section{Honours, awards, appointments}

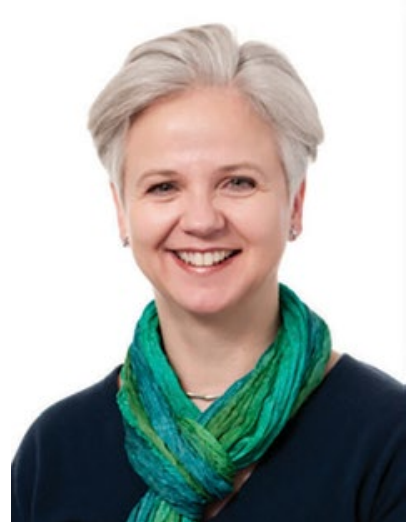

Jane Merivale

Top expert joins indemnity team

The BDA has announced Jane Merivale (pictured), former Senior Dento-Legal Advisor and Head of Policy and Technical at Dental Protection, as the latest addition to the team at BDA Indemnity.

Graduating as a dentist with honours from Guy's Hospital, Jane has accumulated two decades of dento-legal experience, while also leading a successful practice in South London. With a Master of Laws (LLM) in Medical Law from Cardiff University, Jane rose up the ranks at Dental Protection to become one of the foremost authorities in her field.

Jane will lead on building and coaching a sector-leading advisory team at the BDA.

\section{Senior Doctorate}

Professor Christopher Lynch was awarded a Senior Doctorate from Cardiff University this summer: a DDSc - Doctor of Dental Sciences. Chris is a Professor of Restorative Dentistry at the University Dental School \& Hospital/University College Cork and also Editor-in-Chief of the Journal of Dentistry. He was awarded the DDSc based on a formal assessment of his submitted publications which dealt with teaching, assessment and general practice surveys, many of which were published in the $B D J$.
Professor Lynch is the third ever Senior Doctorate in Dentistry from Cardiff, the previous recipients being Paul Dummer and Jon Shepherd.

\section{Outstanding Innovation Award}

The British Society of Paediatric Dentistry (BSPD) Outstanding Innovation Award is open for entries until 31 December 2019. To enter, you must be a BSPD member and your child oral health initiative should be outstanding. For more information visit https://www. bspd.co.uk/Professionals/Awards-and-Prizes.

\section{PEC by-election}

Mark Bishop, a retired endodontist from Hastings, has won election to the BDA's Principal Executive Committee (PEC). The by-election, to one of the PEC's three seats elected on a UK-wide basis, was called following the resignation of incumbent Len D'Cruz. 